\title{
Endoscopic Full-Thickness Resection for Gastric Subepithelial Lesions Arising from the Muscularis Propria
}

\author{
Ah Lon Jung, Sang Wook Park, Gun Young Hong, Hyeong Chul Moon and Seo Joon Eun \\ Division of Gastroenterology, Department of Internal Medicine, Kwangju Christian Hospital, Gwangju, Korea
}

Most cases of gastric subepithelial lesions follow a good clinical course; however, some lesions progress to malignant tumors, and treatment of tumors with a high risk of malignancy is essential. Surgical excision has been the primary treatment for tumors originating from the propria muscle layer, but it has the disadvantages of being invasive and causing postoperative functional abnormalities. With the development of endoscopic techniques and instruments, the role of endoscopic resection, which is a less invasive method for the removal of gastric subepithelial lesions, has been attracting attention. We performed an endoscopic fullthickness resection for 8 patients with gastric subepithelial lesions originating from the muscularis propria. No fatal complications occurred. Our findings suggest the need to develop various devices for resection and closure and to accumulate further experience through additional studies to prevent complications and specimen loss. Clin Endosc 2021;54:131-135

Key Words: Endoscopic full-thickness resection; Gastric subepithelial lesions; Gastrointestinal stromal tumors

\section{INTRODUCTION}

As the use of endoscopy in medical examination has become more common, the frequency of gastric subepithelial lesions that are accidentally discovered is also increasing. Most gastric subepithelial lesions result in a good clinical course and final outcome. However, some lesions can progress to malignant tumors, especially those originating from the muscularis propria layer, represented by gastrointestinal stromal tumors (GISTs). ${ }^{1}$ To date, surgical treatment has been the first choice for complete resection of subepithelial lesions originating from the muscularis propria layer. ${ }^{2}$ However, surgical resection is invasive, often involves the loss of a large part of the organ, and can lead to postoperative functional disorders. In addition,

Received: March 5, 2020 Revised: May 15, 2020

Accepted: May 21, 2020

Correspondence: Sang Wook Park

Division of Gastroenterology, Department of Internal Medicine, Kwangju Christian Hospital, 37 Yangnim-ro, Nam-gu, Gwangju 61661, Korea

Tel: +82-62-650-5023, Fax: +82-62-650-5116, E-mail: kch20113@hanmail.net

ORCID: https://orcid.org/0000-0002-9556-0398

cc This is an Open Access article distributed under the terms of the Creative Commons Attribution Non-Commercial License (http://creativecommons.org/ licenses/by-nc/3.0) which permits unrestricted non-commercial use, distribution, and reproduction in any medium, provided the original work is properly cited. evaluation of the extent of resection necessary is limited for tumors that grow toward the gastric lumen because the inside of the stomach cannot be observed during surgery. Moreover, lesions adjacent to the gastroesophageal junction and posterior wall of the gastric body are often difficult to access surgically and endoscopic assistance may be required.

Recently, the safety of endoscopic treatment for gastrointestinal perforation that occurs after the procedure has increased to a great extent. ${ }^{3}$ Therefore, to increase the en bloc resection rate of subepithelial lesions originating from the muscularis propria, endoscopic full-thickness resection (EFTR) is actively performed, and its efficiency and safety have been reported. ${ }^{4}$

However, data in South Korea are insufficient regarding EFTR without laparoscopic assistance for subepithelial lesions originating from the muscularis propria. Therefore, we report our experiences with EFTR for gastric subepithelial lesions.

\section{CASE REPORT}

\section{Patients}

The inclusion criteria were lesions ranging from 1 to $3 \mathrm{~cm}$ in length (long axis) and originating from the muscularis propria layer on endoscopic ultrasonography (EUS). The exclusion 
criteria were lesions $>3 \mathrm{~cm}$ in length or those that had a high likelihood of malignancy, such as the presence of ulcers on the surface of the lesion. From September 2016 to August 2019, 8 patients ( 6 men and 2 women; age range, $42-76$ years) were diagnosed as having subepithelial lesions originating from the muscularis propria layer by upper gastrointestinal endoscopy and EUS. As a linear probe EUS device without a Doppler function was used, the presence or absence of an epiploic artery passing near the lesion was not confirmed. The lesion size (long axis) ranged from 10 to $27 \mathrm{~mm}$, and the lesions were located at the fundus $(n=2)$, body $(n=5)$, and antrum $(n=1)$.

\section{Instruments}

The equipment used for the procedure included the following: electronic gastroscope (GIF-Q260J; Olympus Co., Tokyo, Japan), endoscopic $\mathrm{CO}_{2}$ regulation unit (Olympus UCR; Olympus), dual knife (KD-650; Olympus), IT knife (KD-611 L; Olympus), hook knife (KD-620 LR; Olympus), hemostatic clip (HX-610-090L and HX-110LR; Olympus), and electrosurgical unit (Erbe VIO300D; Erbe Elektromedizin GmbH, Tübingen, Germany).

\section{Endoscopic full-thickness resection procedure}

Most patients underwent conscious sedation using intravenous injections of midazolam and propofol. In case of gastric wall perforation, $\mathrm{CO}_{2}$ was used to quickly absorb and dissipate the air entering the abdominal cavity. First, the extent of resection was determined by marking around the lesion using a coagulation wave. Then, the mucosa and submucosa covering the lesion were removed with a snare to expose the lesion. When the lesion was sufficiently exposed up to the gastric lumen and the boundary was confirmed, a small perforation was made through an incision at the border of the lesion using an incision knife. Then, the IT knife was inserted in the perforation hole, and the entire layer around the lesion was cut. When the circumferential resection was almost complete, the snare was used to finish the en bloc resection. After resection, the endoscopist confirmed the absence of bleeding or residual tissue in the perforation area. The procedure was considered complete after the perforation was sealed sequentially from the boundary to the center with endoscopic metal clips (Fig. 1).
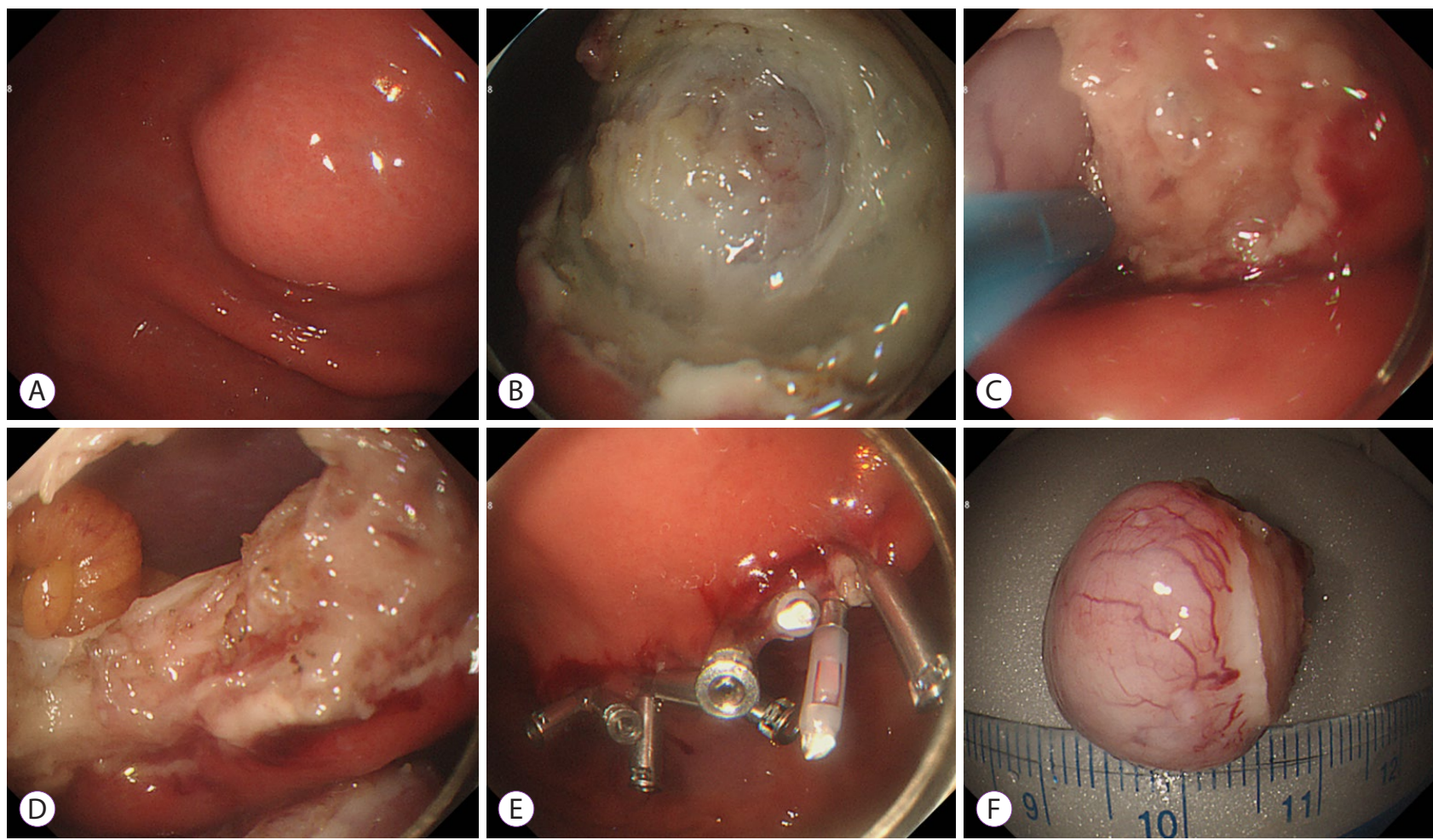

Fig. 1. Endoscopic full-thickness resection of a subepithelial lesion originating from the muscularis propria. (A) A subepithelial lesion originating from the muscularis propria. (B) By using a snare, the mucosa and submucosa covering the lesion are removed to expose the lesion. (C) A small perforation is made through an incision at the border of the lesion by using an incision knife. Then, an IT knife is inserted in the perforation hole, and the entire layer around the lesion is cut. (D) The perforation after complete resection with a snare. (E) The perforation is sealed with endoscopic metal clips. (F) Resected tissue (intraperitoneal lesions, mostly covered with normal serosa). 


\section{Sample processing}

After EFTR, the tissues were immunohistochemically stained with C-Kit, CD34, actin, and S-100, and mitotic counts were determined.

\section{Postprocedural treatment}

Just before and after EFTR, a proton pump inhibitor (esomeprazole $40 \mathrm{mg}$ per day) and broad-spectrum intravenous antibiotics were administered. Fasting was maintained for 2-3 days after the procedure. An oral proton pump inhibitor (esomeprazole $40 \mathrm{mg}$ per day) was administered for 2 months after discharge.

\section{Results}

The clinical and pathological findings and characteristics of ETTR are summarized in Table 1 . The success rate was $100 \%$. The mean procedure time was 66 minutes (range, 25-96 minutes), and the mean size (long-axis length) of the resected specimens was $16.3 \mathrm{~mm}$ (range, 10-27 mm). The final pathological diagnosis was GIST with a low risk of malignancy (mitotic count $<5 / 50$ high power field [HPF]). En bloc resection was successful in all the patients. However, 4 of the 8 patients were considered for $\mathrm{RX}$ resection for histological examination.

No procedure-related deaths or serious complications occurred. Pneumoperitoneum occurred in all the patients but was asymptomatic, and absorbed and disappeared spontaneously. In all the patients, the white blood cell count and C-reactive protein level were elevated after the procedure but decreased in a few days after administration of antibiotics. No signs of fever and peritoneal irritation were found. One case of bleeding occurred on the same day of the procedure, and endoscopic hemostasis was successfully performed. The mean hospital stay was 8.3 days (range, 5-18 days). Most patients were hospitalized within 8 days. However, 1 patient was scheduled to be discharged 6 days after the procedure, but the discharge was delayed because of medical examination, consultation, and treatment for dizziness. The symptom already existed before the procedure, and no abnormality was found in the test. Follow-up endoscopy was performed at 6-month intervals until 2 years after the procedure and at 1-year intervals thereafter. The mean follow-up period was 14 months (range, 5-40 months). None of the patients had a recurrence.

Table 1. Results and Clinical and Pathological Features of Endoscopic Full-Thickness Resection

\begin{tabular}{|c|c|c|c|c|c|c|c|c|c|c|c|c|c|}
\hline Age & Sex & Location & $\begin{array}{l}\text { Layer } \\
\text { (EUS) }\end{array}$ & $\begin{array}{l}\text { Size } \\
(\mathrm{mm})\end{array}$ & $\begin{array}{l}\text { Closure } \\
\text { method }\end{array}$ & $\begin{array}{l}\text { Time } \\
(\mathrm{min})\end{array}$ & $\begin{array}{l}\text { Suc- } \\
\text { cess }\end{array}$ & $\begin{array}{l}\text { Pathological } \\
\text { diagnosis }\end{array}$ & $\begin{array}{c}\text { R0 } \\
\text { resection }\end{array}$ & $\begin{array}{l}\text { Compli- } \\
\text { cation }\end{array}$ & $\begin{array}{c}\text { Hospital } \\
\text { stay } \\
\text { (days) }\end{array}$ & $\begin{array}{l}\text { Follow- } \\
\text { up } \\
\text { (mo) }\end{array}$ & $\begin{array}{l}\text { Recur- } \\
\text { rence }\end{array}$ \\
\hline 42 & $\mathrm{M}$ & Antrum (GC) & PM & $17 \times 12$ & Clip-assisted & 89 & Yes & $\begin{array}{c}\text { GIST (mitosis } \\
<5 / 50 \mathrm{HPF} \text { ) }\end{array}$ & R0 & None & 6 & 40 & None \\
\hline 54 & M & $\begin{array}{l}\text { Upper body } \\
\text { (GC) }\end{array}$ & PM & $15 \times 15$ & Clip-assisted & 95 & Yes & $\begin{array}{c}\text { GIST (mitosis } \\
<5 / 50 \mathrm{HPF} \text { ) }\end{array}$ & $\mathrm{RX}$ & None & 8 & 17 & None \\
\hline 63 & $\mathrm{~F}$ & $\begin{array}{l}\text { Upper body } \\
\text { (PW) }\end{array}$ & PM & $20 \times 20$ & Clip-assisted & 96 & Yes & $\begin{array}{c}\text { GIST (mitosis } \\
<5 / 50 \mathrm{HPF} \text { ) }\end{array}$ & $\mathrm{RX}$ & None & 18 & 14 & None \\
\hline 49 & M & $\begin{array}{l}\text { Upper body } \\
\text { (GC) }\end{array}$ & PM & $27 \times 22$ & Clip-assisted & 80 & Yes & $\begin{array}{l}\text { GIST (mitosis } \\
<5 / 50 \mathrm{HPF} \text { ) }\end{array}$ & $\mathrm{RX}$ & None & 7 & 13 & None \\
\hline 76 & $\mathrm{M}$ & Fundus & PM & $15 \times 10$ & Clip-assisted & 25 & Yes & $\begin{array}{l}\text { GIST (mitosis } \\
<5 / 50 \mathrm{HPF} \text { ) }\end{array}$ & R0 & None & 7 & 11 & None \\
\hline 58 & M & Fundus & PM & $10 \times 8$ & Clip-assisted & 45 & Yes & $\begin{array}{l}\text { GIST (mitosis } \\
<5 / 50 \mathrm{HPF} \text { ) }\end{array}$ & R0 & $\begin{array}{l}\text { Bleed- } \\
\text { ing-he- } \\
\text { mostasis }\end{array}$ & 7 & 6 & None \\
\hline 63 & M & $\begin{array}{l}\text { Upper body } \\
\text { (PW) }\end{array}$ & PM & $12 \times 8$ & Clip-assisted & 54 & Yes & $\begin{array}{c}\text { GIST (mitosis } \\
<5 / 50 \mathrm{HPF} \text { ) }\end{array}$ & $\mathrm{RX}$ & None & 5 & 6 & None \\
\hline 46 & F & $\begin{array}{l}\text { Upper body } \\
\text { (PW) }\end{array}$ & PM & $15 \times 15$ & Clip-assisted & 42 & Yes & $\begin{array}{c}\text { GIST (mitosis } \\
<5 / 50 \mathrm{HPF} \text { ) }\end{array}$ & R0 & None & 8 & 5 & None \\
\hline
\end{tabular}

EUS, endoscopic ultrasound; GC, great curvature; GIST, gastrointestinal stromal tumor; HPF, high power field; PM, muscularis propria; PW, posterior wall. 


\section{DISCUSSION}

Laparoscopic wedge resection is a common treatment for subepithelial lesions originating from the muscularis propria. However, an excessive amount of normal stomach tissue can be removed in this procedure, which results in structural deformation, and depending on the location of the lesion, laparoscopic access may be difficult. In addition, when the lesion protrudes toward the lumen of the gastrointestinal tract, the extent of the lesion on the peritoneal side may be difficult to determine. As a less invasive alternative, endoscopic resection can be considered. However, if the lesion originates from the muscularis propria layer, complete resection using the conventional submucosal resection method is challenging and perforation is difficult to avoid when attempting a sufficient resection. With the development of endoscopic techniques, the gastrointestinal perforation that occurs during the procedure can be managed without any significant problems by performing a proper endoscopic closure. To completely remove the lesion without remnant tissue, complete removal of the lesion including all layers of the gastric wall and anastomosis of the perforation site may be more effective after removal of the lesion including that from the gastrointestinal layer.

Zhou et al. were the first to report 26 cases of subepithelial lesions arising from the muscularis propria that were treated using EFTR. ${ }^{5}$ They sutured using metal clips and an endoloop without laparoscopic assistance in 2011. ${ }^{5}$ All the lesions were completely resected, with no serious complications and recurrence during the follow-up period. Feng et al. reported 48 cases treated with resection and suturing using the same method. ${ }^{6}$ Huang et al. reported 35 cases and Ye et al. reported 51 cases in 2014. ${ }^{7.8}$ In all these reports, no serious complications or recurrence were observed. However, in the study by Ye et al., the excised specimen in 1 of the 51 cases was dropped into the abdominal cavity, and the procedure was completed with laparoscopic assistance. ${ }^{8}$ Similarly, we had difficulty avoiding dropping of the specimen into the gastric wall defect during the procedure. However, a dual channel gastroscope can be used for the procedure, and gripping the excised tissue with forceps during the last excision step can prevent sample loss.

In our patients, all GISTs were endoscopically resected en bloc, but 4 of the 8 patients were considered for RX resection for histological examination. This is because the gastric mucosa and submucosa were removed at the first stage of the procedure and sent to the pathology department with the capsule exposed. Moreover, in the process of removing the lesion, the submucosal tissue near the capsule was damaged. As a method that can be considered to avoid RX resection, endoscopic sub- mucosal dissection may be considered. However, in the case of GIST originating in the proper muscle layer, complete excision of the lesion while leaving the serosal layer is difficult and time consuming. This is especially true if the lesion protrudes out of the stomach. ${ }^{5,9}$ In the case of surgical resection of GISTs, tumor rupture or intraperitoneal bleeding seems to be a major risk factor of recurrence. In addition, the 3-year relapse-free survival was reported to be similar between R0 resection (80\%) and rupture-free R1 resection (79\%). ${ }^{10}$

After the procedure, postoperative adjuvant therapy should be considered for patients with high risk of malignancy (tumor size $>5 \mathrm{~cm}$ and mitotic count $>5 / 50 \mathrm{HPF}$; tumor size $>10$ $\mathrm{cm}$ and mitotic count $>10 / 50 \mathrm{HPF}$ ). At this time, imatinib mesylate therapy may be considered as the primary treatment. ${ }^{11}$

If the size of the gastric wall defect after the procedure is large, it is not easy to suture with only a metal clip. This can be supplemented with an additional endoloop. In addition, devices such as an over-the-scope clip and endoscopic suture device seem useful for easier closure, ${ }^{12,13}$ although we did not use any of these devices in our study. In conclusion, development of various devices for resection and closure and accumulation of further experience through additional studies are necessary to prevent complications and specimen loss.

Conflicts of Interest

The authors have no potential conflicts of interest.

Funding

None.

Author Contributions

Conceptualization: Ah Lon Jung, Sang Wook Park

Data curation: ALJ, Seo Joon Eun

Formal analysis: ALJ

Investigation: ALJ, SJE

Methodology: SWP

Project administration: SWP

Resources: Hyeong Chul Moon

Software: ALJ

Supervision: Gun Young Hong

Validation: SWP

Visualization: ALJ

Writing-original draft: ALJ

Writing-review\&editing: ALJ, SWP, GYH, HCM, SJE

ORCID

$\begin{array}{ll}\text { Ah Lon Jung: } & \text { https://orcid.org/0000-0003-3983-7986 } \\ \text { Sang Wook Park: } & \text { https://orcid.org/0000-0002-9556-0398 } \\ \text { Gun Young Hong: } & \text { https://orcid.org/0000-0002-9802-8348 } \\ \text { Hyeong Chul Moon: } & \text { https://orcid.org/0000-0003-2428-9753 } \\ \text { Seo Joon Eun: } & \text { https://orcid.org/0000-0002-4852-2663 }\end{array}$




\section{REFERENCES}

1. Lim YJ, Son HJ, Lee JS, et al. Clinical course of subepithelial lesions detected on upper gastrointestinal endoscopy. World J Gastroenterol 2010;16:439-444.

2. Ponsaing LG, Hansen MB. Therapeutic procedures for submucosal tumors in the gastrointestinal tract. World J Gastroenterol 2007;13:33163322 .

3. Schmidt A, Fuchs KH, Caca K, Küllmer A, Meining A. The endoscopic treatment of latrogenic gastrointestinal perforation. Dtsch Arztebl Int 2016;113:121-128

4. ASGE Technology Committee, Aslanian HR, Sethi A, et al. ASGE guideline for endoscopic full-thickness resection and submucosal tunnel endoscopic resection. VideoGIE 2019;4:343-350.

5. Zhou PH, Yao LQ, Qin XY, et al. Endoscopic full-thickness resection without laparoscopic assistance for gastric submucosal tumors originated from the muscularis propria. Surg Endosc 2011;25:2926-2931.

6. Feng Y, Yu L, Yang S, et al. Endolumenal endoscopic full-thickness resection of muscularis propria-originating gastric submucosal tumors. J Laparoendosc Adv Surg Tech A 2014;24:171-176.

7. Huang LY, Cui J, Lin SJ, Zhang B, Wu CR. Endoscopic full-thickness resection for gastric submucosal tumors arising from the muscularis propria layer. World J Gastroenterol 2014;20:13981-13986.

8. Ye LP, Yu Z, Mao XL, Zhu LH, Zhou XB. Endoscopic full-thickness resection with defect closure using clips and an endoloop for gastric subepithelial tumors arising from the muscularis propria. Surg Endosc 2014;28:1978-1983.

9. Kim SY, Kim KO. Endoscopic treatment of subepithelial tumors. Clin Endosc 2018;51:19-27.

10. McCarter MD, Antonescu CR, Ballman KV, et al. Microscopically positive margins for primary gastrointestinal stromal tumors: analysis of risk factors and tumor recurrence. J Am Coll Surg 2012;215:53-59; discussion 59-60.

11. Korean Gastrointestinal Stromal Tumor Study Group, Kang YK. Clinical practice guideline for adequate diagnosis and effective treatment of gastrointestinal stromal tumor in Korea. J Korean Med Assoc 2007;50:830841.

12. Stavropoulos SN, Modayil R, Friedel D. Current applications of endoscopic suturing. World J Gastrointest Endosc 2015;7:777-789.

13. Guo J, Liu Z, Sun S, et al. Endoscopic full-thickness resection with defect closure using an over-the-scope clip for gastric subepithelial tumors originating from the muscularis propria. Surg Endosc 2015;29:33563362. 